\title{
The role of Lactobacillus reuteri DSM 17938 for the absorption of iron preparations in children with iron deficiency anemia
}

\begin{abstract}
Jeanette Manoppo, MD, PhD', Hilda Tasiringan, $\mathrm{MD}^{2}$, Audrey Wahani, $\mathrm{MD}^{3}$, Adrian Umboh, MD, PhD ${ }^{4}$, Max Mantik, MD, PhD
${ }^{1}$ Division of Gastroentero-hepatology, Department of Pediatrics, Sam Ratulangi University/Prof. Dr. R.D. Kandou Hospital Manado, Manado, ${ }^{2}$ Department of Pediatrics, Sam Ratulangi University/Prof. Dr. R.D. Kandou Hospital Manado, Manado, ${ }^{3}$ Division of Respirology, Department of Pediatrics, Sam Ratulangi University/ Prof. Dr. R.D. Kandou Hospital Manado, Manado, ${ }^{4}$ Division of Nephrology, Department of Pediatrics, Sam Ratulangi University/Prof. Dr. R.D. Kandou Hospital Manado, Manado, ${ }^{5}$ Division of Hemato-Oncology, Department of Pediatrics, Sam Ratulangi University/Prof. Dr. R.D. Kandou Hospital Manado, Manado, Indonesia
\end{abstract}

Purpose: To determine whether Lactobacillus reuteri DSM 17938 plays a role in absorption of iron preparations given to children with iron deficiency anemia (IDA).

Methods: We performed a quasi-experimental study involving pre- and postintervention tests using a control group in North Sulawesi province, Indonesia, between July and September 2017. We conducted a single-blind controlled trial that included primary school children who were diagnosed with IDA based on reticulocyte hemoglobin equivalent (Ret-He) levels $<27.8 \mathrm{pg} / \mathrm{L}$.

Results: A total of 66 children were randomized into 2 groups. Thirty-four children received iron preparations with the addition of $L$. reuteri DSM 17938 (group 1), whereas the other 32 received iron preparations alone (group 2). The baseline Ret-He levels before intervention were similar in both groups. After 14 days of intervention, mean Ret-He level in group 1 changed from $24.43 \pm 1.64$ to $28.21 \pm 1.72 \mathrm{pg} /$ $\mathrm{L}(P=0.000)$. Mean Ret-He level in group 2 changed from $24.31 \pm 1.42$ to $27.03 \pm 2.14 \mathrm{pg} / \mathrm{L}(P=0.000)$. Statistical analysis showed a significant increase in Ret-He levels in both groups; Ret-He levels were significantly higher in the experimental group than in the control group $(P<0.05)$.

Conclusion: Children with IDA receiving iron preparations with L. reuteriDSM 17938 for 14 days show higher Ret-He levels than those receiving iron preparations alone.

Key words: Lactobacillus reuteri, Child, Iron deficiency, Anemia

\section{Introduction}

Anemia is a term that refers to a low value of hemoglobin $(\mathrm{Hb})$ according to age and sex. Iron deficiency anemia (IDA) is the leading cause of anemia. IDA is the most common nutrient deficiency problem in children worldwide, especially in developing countries, including Indonesia. IDA is anemia caused by a reduction in the body's iron reserves. ${ }^{1)}$

Based on the Basic Health Research (Riskesdas) in 2007 showed the prevalence of IDA in children under 5 in Indonesia was around 40\%-45\% and in all children in Indonesia was $70.1 \%$. The Household Health Survey in 2001 showed the prevalence of IDA in infants 0-6 months, infants 6-12 months, and toddlers were 61.3\%, 64.8\%, and 48.1\% respectively. ${ }^{1)}$ Half the incidences of anemia worldwide are IDA. World Health Organization estimated that in 2004, IDA had caused 273,000 deaths, where 45\% occurred in Southeast Asia, 31\% in Africa, 9\% in the eastern Mediterranean, 7\% in America, 4\% in the Western Pacific region, and 3\% in Europe. Among these incidences, $97 \%$ were found in countries with low to medium income levels. IDA caused a decline in labor productivity resulting in a reduction in state revenues in
Corresponding author: Jeanette Manoppo, MD, $\mathrm{PhD}$

Department of Pediatrics, Sam Ratulangi University/Prof. Dr. R.D. Kandou Hospital Manado, Raya Tanawangko street, Manado, North Sulawesi 95115, Indonesia

Tel: +62-431-821652

Fax: $+62-431-859091$

E-mail: j.manoppo@yahoo.com

https://orcid.org/0000-0001-9154-1600

Received: 7 September, 2018

Revised: 22 January, 2019

Accepted: 24 January, 2019

Copyright $\odot 2019$ by The Korean Pediatric Society

This is an open-access article distributed under the terms of the Creative Commons Attribution NonCommercial License (http://creativecommons.org/ licenses/by-nc/4.0/) which permits unrestricted noncommercial use, distribution, and reproduction in any medium, provided the original work is properly cited. 
10 developing countries, with the average income loss amounting to $\$ 16.78$ per capita, or $4 \%$ of the gross income. IDA can lead to various complications, including impaired cognitive function, decreased endurance, delayed growth, decreased activity, and changes in behavior. Therefore the problem of IDA requires appropriate treatment and prevention. Patients who have been diagnosed with IDA are treated with iron preparation for 3-5 months order to restore $\mathrm{Hb}$ values and iron reserves in the body to the normal states. ${ }^{2)}$

Several animal studies have shown that probiotics are capable of increasing iron absorption in the gut. ${ }^{3)}$ The purpose of this study is to determine whether there is a role of Lactobacillus reuteri DSM 17938 in the absorption of iron preparations in children with IDA.

\section{Materials and methods}

\section{Study population}

The study was conducted in North Sulawesi province in Indonesia from July to September 2017. The study included elementary school children in Tuminting district who suffer from IDA. The inclusion criteria were being aged 5-12 years, meeting the clinical symptoms of IDA with a reticulocyte hemoglobin equivalent (Ret$\mathrm{He}$ ) value of $<27.8 \mathrm{pg} / \mathrm{L}$, having a form signed by parents permitting participation, and having a good nutritional status. Exclusion criteria were having any other infectious diseases, having acute or chronic diarrhea, having consumed probiotic-containing foods in the past few weeks, and suffering from immunodeficiency. This study was conducted with the approval of the medical ethics committee of Sam Ratulangi University Manado and the North Sulawesi Provincial Health Office with the number 151/EC-KEPK/IX/2018.

\section{Clinical data assessment}

There were 72 children who met the inclusion criteria for IDA. Children who fulfilled the inclusion criteria were randomized into 2 different groups. The first was given an iron preparation with the addition of L. reuteri DSM 17938, and the second group was given the iron preparations only. The preparation was administered for 14 days, and then the second Ret-He level was examined on the 14th day of observation. Iron preparations used in this study were $300 \mathrm{mg}$ Sulfas Ferrous (SF) coated tablets given orally, which is equivalent to $60 \mathrm{mg}$ of elemental iron, given with a dose of $2 \times 60 \mathrm{mg}$ of elemental iron. $L$. reuteri DSM 17938 therapy was given $3 \times 10^{8}$ colony forming unit (CFU) per day. Four children, 3 from the first group and 1 from the second, were dropped from the study at the intervention stage because they did not complete the full 14 days of administration. At the second stage of the study, 2 children, 1 from the first group and 1 from the second, were dropped due to blood draw refusal from their parents. A total of 66 children completed the study (Fig. 1).

\section{Statistical analysis}

The study was quasi-experimental which used a single-blindcontrolled trial design, with a pre- and postintervention test using a control group. Data were analyzed using IBM SPSS Statistics ver. 22.0 (IBM Co., Armonk, NY, USA). Univariate analysis was used for the description of sample characteristics. The Kolmogorov-Smirnov test was used as a data normality. An independent $t$ test used to ensure that there was no baseline difference in Ret-Hb between the 2 groups. Paired $t$ test were used to assess the difference in Ret-Hb before and after administration of the preparation in each group. Results were significant if $P<0.05$.

\section{Results}

\section{Sample characteristics}

The 66 children who completed the study were divided into 2 groups. The first group was the experimental grup (children were given iron preparations with the addition of $L$. reuterii DSM 17938), consisting of 34 children. The second group was the controp group, consisting of 32 children given oral iron preparations only. Characteristics of the samples between the 2 groups are described in Table 1. We also tallied $P$ value of each characteristic using independent $t$ test for data that was well distributed, and described them with the mean value. Meanwhile, the Mann-Whitney $U$ test was used to analyze data that was not well distributed, and a median with minimum and maximum values was used to describe them. Among all the characteristics, there are 2 points that have significant values, which are age and reticulocyte $\mathrm{Hb}$ equivalent postintervention (RetHe post).

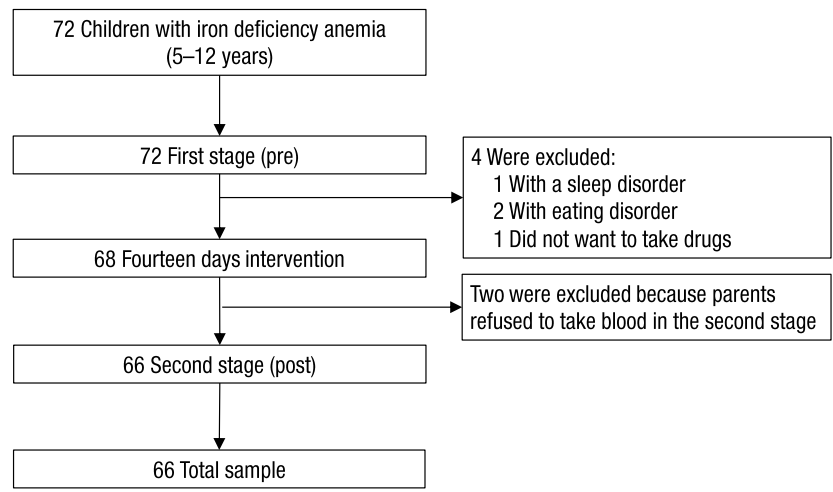

Fig. 1. Study enrollment. We included 72 children with iron deficiency anemia who were then evaluated for reticulocyte hemoglobin equivalent (Ret-He) levels. Four children were excluded for the reasons mentioned above, leaving a total of 68 children. They were divided into 2 different groups receiving different interventions, as mentioned. After 14 days of intervention, Ret-He levels were examined again. Two children were excluded because their parents refused to allow blood sampling in the second stage. The data of a total of 66 children were finally analyzed. 
Table 1. Characteristics of subjects

\begin{tabular}{|c|c|c|c|c|c|}
\hline \multirow{2}{*}{ Characteristic } & \multicolumn{2}{|c|}{ Group $1(n=34)$} & \multicolumn{2}{|c|}{ Group 2 (n=32) } & \multirow{2}{*}{$P$ value } \\
\hline & Mean $\pm S D$ & Median (range) & Mean $\pm S D$ & Median (range) & \\
\hline Age (yr) & - & $7(5-11)$ & - & $9.5(5-11)$ & $0.010^{a)}$ \\
\hline Body weight (kg) & $25.50 \pm 4.26$ & - & $25.66 \pm 4.31$ & - & $0.883^{b)}$ \\
\hline Height (cm) & $120.10 \pm 7.96$ & - & $120.39 \pm 8.11$ & - & $0.885^{\mathrm{b})}$ \\
\hline Hb pre $(g / d L)$ & - & $11.65(9.60-12.40)$ & - & $11.60(9.20-12.90)$ & $0.792^{\mathrm{a})}$ \\
\hline Hb post (g/dL) & $12.20 \pm 0.54$ & - & $12.39 \pm 0.79$ & - & $0.276^{b)}$ \\
\hline Ht pre (\%) & $35.95 \pm 1.81$ & - & $36.55 \pm 2.05$ & - & $0.209^{b)}$ \\
\hline Ht post (\%) & $37.76 \pm 1.60$ & - & $38.04 \pm 2.49$ & - & $0.588^{b)}$ \\
\hline Ret-He pre (pg/L) & $24.43 \pm 1.64$ & - & $24.31 \pm 1.42$ & - & $0.753^{b)}$ \\
\hline Ret-He post (pg/L) & - & $28.50(21.30-30.60)$ & - & $27.50(22.90-30.00)$ & $0.022^{\mathrm{a})}$ \\
\hline
\end{tabular}

Group 1, iron preparations with the addition of Lactobacillus reuteri DSM 17938; group 2, iron preparations alone; SD, standard deviation; Hb pre, hemoglobin level preintervention; Hb post, hemoglobin level postintervention; Ht pre, hematocrit level preintervention; Ht post, hematocrit level postintervention; Ret-He pre, reticulocyte hemoglobin equivalent level preintervention; Ret-He post, reticulocyte hemoglobin equivalent level postintervention.

Boldface indicates a statistically significant difference with $P<0.05$.

a) Mann-Whitney U test. ${ }^{b} \mid$ Independent $t$ test.

Table 2. Assessment of baseline differences in Ret-He levels ( $\mathrm{pg} / \mathrm{L})$ between the 2 groups before intervention using the independent $t$ test

\begin{tabular}{lcccc}
\hline Group & Mean \pm SD & $P$ value & Mean difference & $95 \% \mathrm{Cl}$ \\
\hline 1 & $24.43 \pm 1.64$ & 0.753 & 0.1198 & -0.6366 to 0.8763 \\
2 & $24.31 \pm 1.42$ & & &
\end{tabular}

No baseline difference was observed in reticulocyte-hemoglobin equivalent (Ret-He) levels between the 2 groups before intervention, with $P>0.05$.

Group 1, iron preparations with the addition of Lactobacillus reuteri DSM 17938; group 2, iron preparations alone; SD, standard deviation; Cl, confidence interval.

\section{Baseline difference in Ret-He level between the 2 groups before intervention}

An independent $t$ test was used to ensure that there was no baseline difference in Ret-He levels between the 2 groups before experimental study. The statistical analysis shows no difference in RetHe levels between the 2 groups $(P>0.05)$. The analysis is shown in Table 2.

\section{Comparison of Ret-He level changes after intervention between the 2 groups}

The baseline level and increment of Ret-He levels after intervention in both groups are shown in Table 3. The mean value of RetHe level changes in group 1 was $24.43-1.64 \mathrm{pg} / \mathrm{L}$ vs. $28.21-1.72 \mathrm{pg} /$ L ( $P=0.000$; mean difference, 3.779; 95\% confidence interval [CI], 3.291-4.267). The mean value of Ret-He level changes in group 2 (the control group) was 24.31-1.42 vs. 27.03-2.14 pg/L ( $P=0.000$; mean difference, $2.715 ; 95 \%$ CI, 1.917-3.514). Statistical analysis shows a significant increase in Ret-He levels in both groups after 14 days of intervention, and the mean difference in Ret-He increment was higher in group 1 than in group 2 (3.779 pg/L vs. $2.715 \mathrm{pg} / \mathrm{L})$.

An independent $t$ test was used to compare the difference in RetHe levels between the 2 groups after intervention. The statistical
Table 3. Comparison between pre- and post Ret-He levels (pg/L) after supplemental administration using paired $t$ test analysis

\begin{tabular}{ccccc}
\hline & Mean \pm SD & $P$ value & Mean difference & $95 \% \mathrm{Cl}$ \\
\hline Group 1 $(\mathrm{n}=34)$ & & $<0.001$ & 3.779 & $3.291-4.267$ \\
Ret-He pre & $24.43 \pm 1.64$ & & & \\
Ret-He post & $28.21 \pm 1.72$ & & & \\
Group 2 ( $\mathrm{n}=32)$ & & $<0.001$ & 2.715 & $1.917-3.514$ \\
Ret-He pre & $24.31 \pm 1.42$ & & & \\
Ret-He post & $27.03 \pm 2.14$ & & & \\
\hline
\end{tabular}

Significantly increased Ret-He levels observed in both groups, with group 1 showing a higher mean difference in Ret-He increment than group 2 (3.779 pg/ L vs. $2.715 \mathrm{pg} / \mathrm{L})$

Group 1, iron preparations with the addition of Lactobacillus reuteri DSM 17938 group 2, iron preparations alone; SD, standard deviation; Cl, confidence interval; Ret-He pre, reticulocyte-hemoglobin equivalent level preintervention; Ret-He post, reticulocyte-hemoglobin equivalent level postintervention.

Boldface indicates a statistically significant difference with $P<0.05$.

analysis shows that Ret-He levels in group 1 were significantly higher than those of group $2(P<0.05)$.

\section{Discussion}

Ret-He is a flow cytometry technique and one of the latest hematology tools to estimate $\mathrm{Hb}$ content in reticulocytes in order to describe the actual condition of erythropoiesis and to detect early IDA. Several previous studies have shown the role of Ret-He as a diagnostic tool for IDA. Rungnggu et al.,.) in a study of Ret-He for diagnosis of IDA, suggested that low Ret-He levels were significantly associated with IDA in children $(P=0.005)$, with a cutoff point of Ret-He $27.8 \mathrm{pg} / \mathrm{L}$, sensitivity of $43.8 \%$, specificity of $85.3 \%$, positive predictive value (PPV) of 58.3\% and negative predictive value (NPV) of 76.3\% with odds ratio 4.5 (95\% CI, 1.1-17.7), and it was said 
that Ret-He has high enough specificity that it can be used as a tool for early detection screening of children with IDA. Toki et al.,5) in a study of Ret-He as a potential marker for diagnosis of iron deficiency, showed that there was a correlation between decreased RetHe and iron deficiency $(P=0.016)$. The studies above used Ret-He to diagnose IDA with the cutoff of $<27.8 \mathrm{pg} / \mathrm{L}$. Esther published her thesis on the role of Ret-He in iron deficiency screening in children aged 6 months to 5 years. Of the 94 children who were examined for Ret-He levels with ferritin as a gold standard, Ret-He results were obtained 87 samples a cutoff of 28 pg/L, 81.3\% sensitivity, 93.6\% specificity, 72\% PPV, 96\% NPV, 12.7 LR (+), and 0.2 LR (-). Sanyoto presented results from 87 children with IDA which showed that RetHe can play a role in diagnosis and is an indicator of therapeutic response to iron preparations with $97.2 \%$ sensitivity, 66.67\% specificity, 67.30\% PPV, and 97.14\% NPV. It can be argued that Ret-He levels in the earliest cases of IDA increased when considering $\mathrm{Hb}$, reticulocyte, and erythrocyte index. In addition, Ret-He is also useful for assessing therapeutic response in children with IDA.

The most important function of iron in the body is the development of the nervous system required in myelinization, neurotransmitters, dendritogenesis, and also neural metabolism. ${ }^{6}$ Iron deficiency dramatically affects the cognitive function, behavior, and growth of infants. Iron is also a source of energy for the muscles that affect physical endurance and ability to work primarily in adolescents. In healthy adolescents with no accompanying infectious disease, IDA is most often caused by low iron intake. ${ }^{7)}$ Children with IDA can be given oral elemental therapy with a dose of $3-\mathrm{mg} / \mathrm{kg}$ body weight before meals or $5-\mathrm{mg} / \mathrm{kg}$ body weight after meals divided into 3 doses. Iron deficiency resulting from inflammatory or infectious processes can be treated with 3-6 $\mathrm{mg} / \mathrm{kg}$ body weight per day of iron therapy for 3-6 weeks. ${ }^{8)}$ In this study, the SF iron preparation is from a government program and is usually used to treat cases of anemia in children and pregnant women. This SF is obtained from the provincial health office. One 300-mg tablet of SF is equivalent to 60 $\mathrm{mg}$ of elemental iron. So, because the average weight of the children sampled was $25.603-26.719 \mathrm{~kg}$, they were given a dose of $2 \times 1$ SF sugar-coated tablet each day for 14 days.

L. reuteri is part of the gastrointestinal microflora in infants and children. $L$. reuteri ferments lactose carbohydrates or undigested oligosaccharides in the large intestine to produce an acidic atmosphere that improves bowel motility by improving bowel peristalsis movement, which finally helps absorption and aids in fecal outbreaks. Reuteri is suspected to have an anti-Helicobacter pylori effect. ${ }^{9}$ For the addition of intestinal microbiota, in this study, we used a single strain probiotic $L$. reuteri DSM 17938 given with a dose of $3 \times 10^{8}$ CFU daily for 14 days.

In this study, Ret-He examination was done in elementary school children aged 5-12 years, who were found to be pale on physical examination and had a PCV value $\leq 36 \%$. The selected school is a school which, according to mapping data from the local primary healthcare provider, has a high rate of anemia. Before the first stage of the examination, a complete history was made for all the subjects, and complete data were gathered along with active phone numbers. The researcher also explained to the parents the planned drug administration and blood test that would be done after 14 days of intervention. Subsequently all the parents signed an informed consent form. After that, the results of examination for a Ret-He $<27.8 \mathrm{pg} / \mathrm{L}$ were evaluated by treatment intervention with subject divided into 2 groups: group 1 was given an iron preparation as well as L. reuteri DSM 17938 and group 2 was given only the iron preparation. Drugs were submitted directly to the patients' parents, along with education on how to use the drugs and what procedures would be done. Subjects do not need to add iron or another probiotic intake from milk or other processed products containing probiotics for 14 days. Monitoring of medication adherence and side effects of the drug followed. This was done through personal contact and one supervisor, who also brought the medication from primary healthcare provider, checking subjects' medication use once every three days. On the 15th day, the $\mathrm{Hb}, \mathrm{Ht}$, and Ret-He levels of the subjects in both groups were examined.

This study supports the theory and previous studies that say that probiotics have a role in iron absorption. Probiotics work directly on epithelial cells to increase the expression and excretion of mucin from goblet cells as well as $\beta$ defensin, which inhibits proliferation of pathogenic or commensal germs and affects the integrity of the mucosal barrier. Probiotics also improve tight junction stability, which reduces the permeability of the pathogens and their products. So, intestinal mucosa does not bind to the pathogen but more to the substances that the body needs, such as iron. Probiotics affect mucosal immunity by increasing the number of sIgA-producing cells in the lamina propria, which prevents colonization on epitel by binding to bacteria and antigens so that it affects gastrointestinal balance. $L$. reuteri improves the apical surface of the intestine that affects divalent metal transporter-1 (DMT-1), which plays a vital role in the absorption of the iron preparation used. ${ }^{10)}$ Administering probiotics together with iron preparations is expected to provide better outcomes for patients with IDA, provided that the probiotics are administered earlier than iron preparations.

A previous study said that an iron-fortified fermented milk beverage that was added with probiotics increased the iron status of preschoolers after 35 days of consumption. The compound used in fortification is an amino acid clamp iron, which according to the literature dissolves in the intestine and is easily absorbed. In addition, Lactobacillus may help balance intestinal microflora and improve nutritional availability. ${ }^{11)}$

Paracellular permeability is determined by the structure of the complex of junctions that are localized close to the epithelial cells, where the body gets the input of iron from food in the gut. The iron absorption process occurs mostly in the duodenum and proximal jejunum. The apical membrane of enterocytes in the duodenum acts 
as a transporter for iron from the intestine lumen to the enterocyte. The most important transporter molecule is DMT-1, with $L$. reuteri's role on the surface of the intestine and effect on the intestinal paracellular permeability affecting DMT-1 in iron absorption. ${ }^{12)}$

Sazawal et al. ${ }^{13)}$ conducted a study on the effects of Bifidobacterium lactis HNO19 and milk containing oligosaccharide prebiotic on iron status, anemia, and growth in children aged 1-4 years. Results of this study were that consumption of milk with added probiotics and prebiotics within 1 year reduced the risk of anemia and iron deficiency by $45 \%$ (95\% CI, 115; 66\%; $P=0.01$ ) and caused weight gain of $0.13 \mathrm{~kg} / \mathrm{yr}$ (95\% CI, 0.03-0.23; $P=0.02)$. The study concluded that preschool children that were given probiotic-enriched fermented milk showed a slight decrease in iron deficiency and an increase in body weight.

Emara et al. ${ }^{14)}$ from Egypt conducted a double-blind clinical trial to find out whether the addition of $L$. reuteri probiotics to the standard triple therapy would improve the eradication of Helicobacter pylori. In conclusion, the addition of $L$. reuteri probiotics can improve the Gastrointestinal Symptom Rating Scale score of dyspeptic patients receiving triple therapy.

Silva et al., ${ }^{11)}$ in previous experiments in 2002, showed a significant increase in ferritin levels observed in 25\% of preschool children after a 35-day intervention with probiotic microorganisms. Siva et al., ${ }^{11)}$ in subsequent trials in 2008, evaluated the effects of fermented milk which was fortified with iron chelation with and without probiotic bacteria (Lactobacillus acidophilus) on growth and iron status of preschoolers in long-term intervention. The result was a positive correlation $(P=0,02)$ between iron intake and $\mathrm{Hb}$ in the probiotic group. Results also showed a higher increase $(38.2 \%, n=45)$ in the $\mathrm{Hb}$ level compared to the group given drink without probiotic microorganisms (control) (30.2\%, $\mathrm{n}=84$ ). Hematologic analysis performed in this study was based on the hypothesis that probiotics would increase the bioavailability and storage of iron in the body. The results of this study showed a significant increase in mean corpuscular hemoglobin concentration (MCHC) found in groups given probiotic beverages, indicating higher red blood cell saturation and reduced hypochromia in children. ${ }^{11)}$ Oda et al. ${ }^{15)}$ in their study also showed that $L$. acidophilus increased the bioavailability of fermented iron in an animal experiment.

The study conducted by Zimmermann et al. ${ }^{16)}$ showed that iron fortification in children causes the gut microbiota profile to be more pathogenic due to the increased in pathogenic enterobacteria and decrease in Lactobacilli, and may increase the frequency of diarrhea. Iron supplementation can lead to the formation of free radicals, which have a negative impact on child endurance. In addition, at the time of getting iron supplementation, there is an imbalance of intestinal microbiota due to increase in intestinal bacteria pathogens, which in turn increases the incidence of diarrhea. It has been explained that supplementation and fortification is the main effort in tackling the anemia problem, but, on the other hand, may also have the negative impact of microbiota imbalance in the gastrointestinal tract, which can cause diarrhea. Therefore, we need a way to overcome this using probiotics to maintain the number of Lactobacilli and bifidobacteria in the intestine during the administration of iron. This step is expected to maintain the balance of intestinal microbiota and suppress the increase of enteropathogenic bacteria so that the program of supplementation and iron fortification can still be carried out without worrying about its negative effects. This study describes the role of intestinal microbiota in the absorption of substances that the body needs by the intestine, such as the absorption of iron. The failure of IDA therapy that has occurred so far may be related to intestinal microbiota balance. Administering probiotics to children with IDA is expected to provide good outcomes. In cases of IDA where probiotics are not available, it is advisable to consume food products that contain probiotics. ${ }^{17)}$

Hoppe et al. ${ }^{18)}$ had a pre-post study in women of reproductive age using probiotic strain Lactobacillus pantarum $299 \mathrm{v}$ with serum iron (SI) as a study indicator. The 21 subjects were divided into 2 groups, 10 in the control group and 11 in the case group, and the results obtained show that there was a significant increase in iron absorption in the case group, which was given a drink containing $L$. pantarum $299 \mathrm{v}$, compared with the control group with $P=0.08$.

Most studies of probiotics associated with iron absorption concluded that there was a correlation between probiotics and iron absorption, but there were also previous studies whose results differ from this study. Agustina et al. ${ }^{19)}$ conducted a study in Indonesia in 2013 using milk intervention with probiotics L. reuteri and Lactobacillus casei in children aged 1-6 years. The results concluded that milk intervention with the probiotics $L$. reuteri significantly increased body weight, but not iron and zinc status. Asemi et al. ${ }^{20}$ ) studied the effect of daily consumption of yogurt probiotics on levels of calcium, iron, and liver enzymes in pregnant women. The results of this study suggest that consumption of probiotic yogurt retains serum calcium levels compared with those not consuming yogurt $(P=0.01)$, this significant difference is shown by a significant decrease in serum calcium levels $(-1.7 \mathrm{mg} / \mathrm{dL}, P<0.0001)$. But there was no significant difference between the groups of pregnant women who consumed yogurt and those who did not consume yogurt in serum iron and liver enzyme levels. This may be related to confounding variables of the daily consumption patterns of the study subjects.

This study has limitations. First, researchers cannot exclude all confounding variables that may affect results after the intervention. For example, some children's diets that may not have been accurately reported by parents. Also, 2 blood tests were done during 14 days cause some samples dropped. Based on the results of this study, it can be concluded that intervention with iron preparations and L. reuteri DSM 17938 in children with IDA for 14 days leads to a higher increase in levels of Ret-He than does intervention with iron preparations only. L. reuteri DSM 17938 has a beneficial role in 
the absorption of iron from the intestinal mucosa.

\section{Conflicts of interest}

No potential conflict of interest relevant to this article was reported.

\section{References}

1. Reniarti L, Susanah S, Suryawan N, Achmad RH, Idjradinata P. Iron deficient anemia. In: Garna H, Nataprawira MH. Guidelines for diagnosis and therapy of child health. 4th ed. Bandung: Child Health Department of Medical Faculty of University Padjajaran, 2012:28387.

2. Pasricha SR, Drakesmith H, Black J, Hipgrave D, Biggs BA. Control of iron deficiency anemia in low- and middle-income countries. Blood 2013;121:2607-17.

3. Scholz-Ahrens KE, Schrezenmeir J. Inulin and oligofructose and mineral metabolism: the evidence from animal trials. J Nutr 2007;137 (11 Suppl):2513S-2523S.

4. Rungnggu SL, Wahani A, Mantik M. Reticulocyte hemoglobin equivalent for diagnosing iron deficiency anemia in children. Paediatr Indonesiana 2016;56:90-3.

5. Toki Y, Ikuta K, Yamamoto M, Hatayama M, Shindo M, Fujiya M, et al. Usefulness of reticulocyte hemoglobin equivalent for diagnosis of iron deficiency. Blood 2016;128:3621.

6. Ganz T, Nemeth E. Iron homeostasis in host defence and inflammation. Nat Rev Immunol 2015;15:500-10.

7. Vucic V, Berti C, Vollhardt C, Fekete K, Cetin I, Koletzko B, et al. Effect of iron intervention on growth during gestation, infancy, childhood, and adolescence: a systematic review with meta-analysis. Nutr Rev 2013;71:386-401.

8. Wang B, Zhan S, Gong T, Lee L. Iron therapy for improving psychomotor development and cognitive function in children under the age of three with iron deficiency anaemia. Cochrane Database Syst Rev 2013;(6):CD001444.
9. Anurogo D. Probiotik: problematika dan progresivitasnya. Medicinus 2014;27:46-57.

10. Ohland CL, Macnaughton WK. Probiotic bacteria and intestinal epithelial barrier function. Am J Physiol Gastrointest Liver Physiol 2010;298:G807-19.

11. Silva MR, Dias G, Ferreira CL, Franceschini SC, Costa NM. Growth of preschool children was improved when fed an iron-fortified fermented milk beverage supplemented with Lactobacillus acidophilus. Nutr Res 2008;28:226-32.

12. Hernell 0, Lönnerdal B. Recommendations on iron questioned. Pediatrics 2011;127:e1099-101.

13. Sazawal S, Dhingra U, Dhingra P, Dutta A, Shabir H, Menon VP, et al. Efficiency of red cell distribution width in identification of children aged 1-3 years with iron deficiency anemia against traditional hematological markers. BMC Pediatr 2014;14:8.

14. Emara MH, Mohamed SY, Abdel-Aziz HR. Lactobacillus reuteri in management of Helicobacter pylori infection in dyspeptic patients: a double-blind placebo-controlled randomized clinical trial. Therap Adv Gastroenterol 2014;7:4-13.

15. Oda T, Kado-oka Y, Hashiba H. Effect of Lactobacillus acidophilus on iron bioavailability in rats. J Nutr Sci Vitaminol (Tokyo) 1994;40:6136.

16. Zimmermann MB, Wegmueller R, Zeder C, Chaouki N, Rohner F, Saïssi M, et al. Dual fortification of salt with iodine and micronized ferric pyrophosphate: a randomized, double-blind, controlled trial. Am J Clin Nutr 2004;80:952-9.

17. Quigley EM. Therapies aimed at the gut microbiota and inflammation: antibiotics, prebiotics, probiotics, synbiotics, anti-inflammatory therapies. Gastroenterol Clin North Am 2011;40:207-22.

18. Hoppe M, Önning G, Berggren A, Hulthén L. Probiotic strain Lactobacillus plantarum $299 \mathrm{v}$ increases iron absorption from an ironsupplemented fruit drink: a double-isotope cross-over single-blind study in women of reproductive age. Br J Nutr 2015;114:1195-202.

19. Agustina R, Bovee-Oudenhoven IM, Lukito W, Fahmida U, van de Rest 0, Zimmermann MB, et al. Probiotics Lactobacillus reuteri DSM 17938 and Lactobacillus casei CRL 431 modestly increase growth, but not iron and zinc status, among Indonesian children aged 1-6 years. J Nutr 2013;143:1184-93.

20. Asemi Z, Esmaillzadeh A. Effect of daily consumption of probiotic yoghurt on serum levels of calcium, iron and liver enzymes in pregnant women. Int J Prev Med 2013;4:949-55. 